\title{
Analysis of patch testing in patients with hand eczema at Shenzhen from 2016 to 2019
}

\author{
Yanhua Liang, Xiaomin Zhang, Jingna Zhu, Faizan Ali, Huihui Mo
}

Department of Dermatology, Cosmetology and Venereology, Shenzhen Hospital, Southern Medical University, Shenzhen, Guangdong, China

Adv Dermatol Allergol 2021; XXXVIII (1): 170-172

DOI: https://doi.org/10.5114/ada.2021.104294

The skin is a vital organ that separates the body from its surrounding environment. Therefore, it is vulnerable to environmental triggers including physical, chemical, and biological aggression which may cause diseases such as eczema. Hand eczema (HE) is a broad term used to describe inflammation of the hands. The eruptions may include erythema, infiltration, papules, vesicles and edema in the acute stage while, in the chronic stage, crusting, scaling, hyperkeratosis and fissures will be the dominating symptoms [1]. Subjective symptoms include itching, burning, pain, sleep and mood disturbances [2]. $\mathrm{HE}$ is a common chronic disease with a 1-year prevalence of approximately $5-8 \%$ in the adult population [2], and it has a higher incidence rate in women as compared with men. HE has a significant long-lasting negative impact on quality of life and presents an economic burden for the society [3]. HE is most commonly classified as irritant contact dermatitis (ICD) or allergic contact dermatitis (ACD) [4]. ACD is an eczematous dermatitis caused by a type four hypersensitivity reaction of the skin, while ICD is a nonspecific reaction that occurs after an irritant comes in contact with skin [5]. These 2 types of dermatitis are often indistinguishable clinically. In daily life, the allergic factors may not be noticed by patients, however, as a result of prolonged and repeated exposures, HE develops. Using a standard series of allergens can be helpful in testing when it is impossible to identify an offending agent despite a careful history and clinical examination. Patch testing is the "gold standard" to identify culprit allergen(s) causing ACD [6]. Performing patch testing early upon the disease onset has been demonstrated to be cost effective, and previous studies have shown that patch testing allows for identification of relevant allergens, early resolution of symptoms, and, ultimately, improved quality of life in affected individuals [7].
A retrospective study was conducted involving 977 patients with HE who visited Shenzhen Hospital of the Southern Medical University over a 4 years and 3 months, from January 2016 to December 2019. A detailed record of each patient was taken which included the history of occupational and personal exposure to chemicals, history of atopy, thorough examination of the affected area, its morphology and final diagnosis. Test substances were applied on the upper part of the patients' back with adhesive strips for patch test. The patch test was removed and reactions were evaluated after $48 \mathrm{~h}$. Patients were instructed to wear the patch for $48 \mathrm{~h}$ without removing it and to avoid contact with water. Grading of negative $(-)$ to positive (+ to +++ ) patch test was done according to the International Contact Dermatitis Research Group Criteria [8]. Patients who could not complete the 48-hour testing or have been suspected of being allergic to adhesive strips of the patch testing were excluded. The collected data were analyzed using SPSS (Statistical Package for Social Sciences) version 23.0, with positive patch testing results being presented by frequency and percentage. The $\chi^{2}$ test was carried out to estimate the association and significant difference among categorical variables, with $p$-value $<0.05$ being considered as being statistically significant.

The mean age of the patients was $35.73 \pm 14.05$ years. The youngest patient in the study was 4 years old and the oldest was 89 , with the mostly affected being $25-$ 50 years old in males and $20-45$ in females. As shown in Table 1, 8.98\% of cases were aged less than 20 years old while majority of the patients (91.02\%) were more than 20 years old. According to the positive results of patch tests, 765 (87.33\%) HE patients had at least one allergen, more frequently in women than in men (531 vs. 235). The most common allergens were nickel (65.07\%) and copper (41.45\%).

Address for correspondence: Yanhua Liang, Department of Dermatology, Cosmetology and Venereology, Shenzhen Hospital, Southern Medical University, Shenzhen, Guangdong, China, e-mail: liangdoctor@163.com Received: 31.01.2020, accepted: 3.03.2020. 
Table 1. The profiling of patch tests in patients with hand eczema

\begin{tabular}{|c|c|c|c|c|c|c|}
\hline \multirow[t]{2}{*}{ No. } & \multirow[t]{2}{*}{ Allergens } & \multicolumn{2}{|c|}{$\begin{array}{c}\text { Male } \\
N \text { (percentage of male) }\end{array}$} & \multicolumn{2}{|c|}{$\begin{array}{c}\text { Female } \\
N \text { (percentage of female) }\end{array}$} & \multirow{2}{*}{$\begin{array}{c}\text { Total } \\
N \text { (percentage of } \\
\text { all cases \%) }\end{array}$} \\
\hline & & $\leq 20$ years & $>20$ years & $\leq 20$ years & $>20$ years & \\
\hline 1 & Nickel chloride & $16(6.81 \%)$ & 149 (63.40\%) & $26(4.90 \%)$ & 338 (63.65\%) & $529(65.07 \%)$ \\
\hline 2 & Copper sulfate & $17(7.23 \%)$ & $94(40.00 \%)$ & 15 (2.82\%) & 211 (39.74\%) & $337(41.45 \%)$ \\
\hline 3 & Methylisothiazolinone & $6(2.55 \%)$ & 45 (19.15\%) & $13(2.45 \%)$ & 95 (17.89\%) & 159 (19.56\%) \\
\hline 4 & Glutaraldehyde & $6(2.55 \%)$ & $33(14.04 \%)$ & $7(1.32 \%)$ & $51(9.60 \%)$ & 97 (11.93\%) \\
\hline 5 & Permanent red & $5(2.13 \%)$ & $17(7.23 \%)$ & $9(1.69 \%)$ & $66(12.43 \%)$ & 97 (11.93\%) \\
\hline 6 & Silver nitrate & $8(3.40 \%)$ & 21 (8.94\%) & $4(0.75 \%)$ & 47 (8.85\%) & $80(9.84 \%)$ \\
\hline 7 & Hansa Yellow & $4(1.70 \%)$ & 19 (8.09\%) & $5(0.94 \%)$ & 50 (9.42\%) & 78 (9.59\%) \\
\hline 8 & Boric acid & $1(0.43 \%)$ & $24(10.21)$ & $3(0.56 \%)$ & 43 (8.10\%) & 71 (8.73\%) \\
\hline 9 & Chlorhexidine & $2(0.85 \%)$ & $23(9.79 \%)$ & $2(0.38 \%)$ & 35 (6.59\%) & 62 (7.63\%) \\
\hline 10 & Naphthy I mix & $7(2.98 \%)$ & $14(5.96 \%)$ & $7(1.32 \%)$ & $34(6.40 \%)$ & $62(7.63 \%)$ \\
\hline 11 & Clove oil & $2(0.85 \%)$ & $20(8.51 \%)$ & $6(1.13 \%)$ & 31 (5.84\%) & $59(7.26 \%)$ \\
\hline 12 & Triclosan & $0(0.00 \%)$ & $12(5.11 \%)$ & $2(0.38 \%)$ & $42(7.91 \%)$ & $56(6.89 \%)$ \\
\hline 13 & Vanillyl alcohol & $5(2.13 \%)$ & $16(6.81 \%)$ & $3(0.56 \%)$ & $29(5.46 \%)$ & $53(6.52 \%)$ \\
\hline 14 & Pigment Violet & $6(2.55 \%)$ & $14(5.96 \%)$ & $5(0.94 \%)$ & $28(5.27 \%)$ & $53(6.52 \%)$ \\
\hline 15 & Paraformaldehyde & $2(0.85 \%)$ & $15(6.38 \%)$ & $2(0.38 \%)$ & $33(6.21 \%)$ & $52(6.40 \%)$ \\
\hline 16 & 2-Chloroacetamide & $2(0.85 \%)$ & $13(5.53 \%)$ & $6(1.13 \%)$ & $31(5.84 \%)$ & $52(6.40 \%)$ \\
\hline 17 & Dimethyl $p$-toluidine & $2(0.85 \%)$ & $10(4.26 \%)$ & $6(1.13 \%)$ & $33(6.21 \%)$ & $51(6.27 \%)$ \\
\hline 18 & Tea tree oil 1 & $(0.43 \%)$ & $12(5.11 \%)$ & $4(0.75 \%)$ & $34(6.40 \%)$ & $51(6.27 \%)$ \\
\hline 19 & Benzoic acid & $4(1.70 \%)$ & $16(6.81 \%)$ & $3(0.56 \%)$ & $26(4.90 \%)$ & 49 (6.03\%) \\
\hline 20 & Benzocaine & $0(0.00 \%)$ & $9(3.83 \%)$ & $2(0.38 \%)$ & 37 (6.97\%) & $48(5.90 \%)$ \\
\hline 21 & Peppermint oil & $3(1.28 \%)$ & $11(4.68 \%)$ & $4(0.75 \%)$ & $29(5.46 \%)$ & $47(5.78 \%)$ \\
\hline 22 & Mercapto mix & $3(1.28 \%)$ & $10(4.26 \%)$ & $5(0.94 \%)$ & $29(5.46 \%)$ & $47(5.78 \%)$ \\
\hline 23 & Hexamethylenetetramine & $2(0.85 \%)$ & $11(4.68 \%)$ & $0(0.00 \%)$ & $34(6.40 \%)$ & 47 (5.78\%) \\
\hline 24 & Coumarin & $3(1.28 \%)$ & $7(2.98 \%)$ & $2(0.38 \%)$ & $33(6.21 \%)$ & 45 (5.54\%) \\
\hline 25 & Ethanediainine & $2(0.85 \%)$ & $9(3.83 \%)$ & $7(1.32 \%)$ & $25(4.71 \%)$ & $43(5.29 \%)$ \\
\hline 26 & Propanediol & $1(0.43 \%)$ & $7(2.98 \%)$ & $2(0.38 \%)$ & $27(5.08 \%)$ & $37(4.55 \%)$ \\
\hline 27 & Salicylic acid & $1(0.43 \%)$ & $9(3.83 \%)$ & $1(0.19 \%)$ & $23(4.33 \%)$ & $34(4.18 \%)$ \\
\hline 28 & Urea-formaldehyde resin & $3(1.28 \%)$ & $5(2.13 \%)$ & $1(0.19 \%)$ & $19(3.58 \%)$ & $28(3.44 \%)$ \\
\hline 29 & Vanillin & $2(0.85 \%)$ & $4(1.70 \%)$ & $2(0.38 \%)$ & $18(3.39 \%)$ & $26(3.20 \%)$ \\
\hline 30 & Diazoalkyl urea & $3(1.28 \%) 2(0.85 \%)$ & $1(0.19 \%)$ & $16(3.01 \%)$ & $22(2.71 \%)$ & \\
\hline
\end{tabular}

$N$-number of cases.

In our study, the minimum duration of the disease was less than 4 weeks and the maximum duration was 17 years. The duration in most patients was 6 to 15 months. There was no statistically significant impact of occupation and duration of the disease on the results of patch testing $(p>0.05)$. Statistically, the occupational character of skin lesions was found in 105 (15.28\%) individuals.

In previous research studies, positive patch testing results were found among most patients with contact dermatitis [9] and HE [10]. This concept was further supported by the results obtained in this study that positive patch testing results in allergens were found among majority (87.33\%) of the HE patients. Males and females more than 20 years old were more likely to show a positive result $(p<0.05)$. Females were significantly more likely to show a positive response $(p<0.05)$ than males. This may relate to women who are more often exposed to house work, which leads to water loss from the epidermal layer, thus resulting in dryness, cracking, and inflammation [11], making them more prone to HE [12].

According to the results of patch tests, 72 (43.64\%) males and 145 (39.84\%) females were double positive for nickel and copper. Thus, it is unlikely that the high allergic reaction to copper is caused by cross-reactivity. In 
this study, the concentration of copper sulfate was 5\% in pet. The International Contact Dermatitis Research Group recommends application of 1\% copper sulfate in aq. or pet. [13], however, Wohrl et al. suggested that concentrations of $<5 \%$ may not be sensitive enough to detect all copper hypersensitivities [14]. Therefore, a compromise way would be to make a preliminary diagnosis with $5 \%$ copper sulfate, and then conduct a serial dilution test [15] to confirm the positive result.

Our results indicated that nickel chloride was the most common allergen responsible for induction of ACD in HE patients. The majority of the patients were female, most of whom were 20-45 years old. These findings were crucial to the education, long-term management and treatment of patients with HE. Patch testing is a valuable diagnostic tool for early identification of culprit allergens in $\mathrm{HE}$.

\section{Conflict of interest}

The authors declare no conflict of interest.

\section{References}

1. Menné T, Johansen J, Sommerlund M, et al. Hand eczema guidelines based on the Danish guidelines for the diagnosis and treatment of hand eczema. Contact Dermatitis 2011; 65: 3-12.

2. Agner T, Elsner P. Hand eczema: epidemiology, prognosis and prevention. J Eur Acad Dermatol 2020; Suppl 1: 4-12.

3. Graversgaard C, Agner T, Jemec G, et al. A long-term followup study of the Hand Eczema Trial (HET): a randomized clinical trial of a secondary preventive programme introduced to Danish healthcare workers. Contact Dermatol 2018; 78: 329-34.

4. Zimmer K, Armbrecht E, Burkemper N. The association of smoking with contact dermatitis and hand eczema - a review. Int J Dermatol 2018; 57: 375-87.

5. Bains S, Nash P, Fonacier L. Irritant contact dermatitis. Clin Rev Allergy Immunol 2019; 56: 99-109.

6. Sundquist B, Yang B, Pasha M. Experience in patch testing: a 6 -year retrospective review from a single academic allergy practice. Ann Allergy Asthma Immunol 2019; 122: 502-7.

7. Rajagopalan R, Anderson R. Impact of patch testing on dermatology-specific quality of life in patients with allergic contact dermatitis. Am J Contact Dermatol 1997; 8: 215-21.

8. Pongpairoj K, Ale I, Andersen K, et al. Proposed ICDRG classification of the clinical presentation of contact allergy. Dermatitis 2016; 27: 248-58.

9. Kasumagic-Halilovic E, Ovcina-Kurtovic N. Analysis of epicutaneous patch test results in patients with contact dermatitis. Med Arch 2018; 72: 276-9.

10. Vigneshkarthik N, Ganguly S, Kuruvila S. Patch test as a diagnostic tool in hand eczema. J Clin Diagn Res 2016; 10: 4-7.

11. Egawa G, Kabashima K. Multifactorial skin barrier deficiency and atopic dermatitis: essential topics to prevent the atopic march. J Allergy Clin Immunol 2016; 138: 350-8.

12. Machedeleidt W, Sandhoff K. Deficiency of epidermal protein bound omega-hydroxyceramides in atopic dermatitis. J Invest Dermatol 2002; 119: 116-23.
13. Simong F, Annesofifie F, Jacob T. Copper hypersensitivity. Contact Dermatitis 2014; 71: 191-201.

14. Wohrl S, Hemmer W, Focke M, et al. Copper allergy revisited. J Am Acad Dermatol 2001; 45: 863-70.

15. Hostynek JJ, Maibach HI. Copper hypersensitivity: dermatologic aspects. Dermatol Ther 2004; 17: 328-33. 